BMJ Open

Sport \&

Exercise

Medicine

\title{
Cracking the code for maintaining quality training in Olympic distance triathlon: lessons learnt from a squad of elite Scandinavian athletes
}

\author{
Corrie Myburgh, ${ }^{1}$ Tobias Hansen, ${ }^{1}$ Anders Holm Beck, ${ }^{1}$ Eleanor Boyle ${ }^{1,2}$
}

To cite: Myburgh C, Hansen T, Holm Beck A, et al. Cracking the code for maintaining quality training in Olympic distance triathlon: lessons learnt from a squad of elite Scandinavian athletes. BMJ Open Sport Exerc Med 2017;3:e000274. doi:10.1136/bmjsem-2017000274

Accepted 28 August 2017

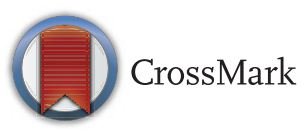

${ }^{1}$ Department of Sports and Clinical Biomechanics, University of Southern Denmark, Odense, Denmark ${ }^{2}$ Dalla Lana School of Public Health, University of Toronto, Toronto, Ontario, Canada

Correspondence to Dr Corrie Myburgh; cmyburgh@health.sdu.dk

\section{ABSTRACT}

Objective High-quality training is a key determinant of performance in the Olympic distance triathlon and is potentially influenced by a unique array of contextspecific biopsychosocial factors. Our objective was to explore and describe these factors among squad members of a university-based, elite Olympic distance triathlete developmental programme.

Method A qualitative investigation using a visual communication tool-assisted focus group and longitudinal semistructured individual interviews was conducted. Responses were solicited from the University of Southern Denmark's elite triathlon team $(n=8)$, and inductive coding from the focus group formed the basis of questions for the two rounds of individual interviews 11 months apart. All interviews were transcribed verbatim and then analysed thematically.

Results Seventeen context-relevant factors were identified and 10 themes emerged, these being 'the cold weather ritual', 'digestive system conditioning', 'the curse of the night owl', 'the strings attached to sponsorship', 'my coach-my rock', 'mood maintenance', 'the asynchronous training rhythm', 'psychological slavery', 'the legacy of the asphalt tattoo' and 'the tension of family and friends'. Conclusions By reflecting on their personal training vortex, elite triathletes were able to provide contextrelevant insights into the maintenance of training quality over the course of a competitive season. Further research is required to elucidate whether and how biopsycholosocial factors can be modified to optimise the achievement of training goals.

\section{INTRODUCTION}

The Olympic distance triathlon (ODT) is the pinnacle of endeavour for the young, elite-level triathlete. ${ }^{1}$ This triathlon format offers an opportunity to compete at the Olympic games but is also a springboard to ever more lucrative professional careers in the world of swim-bike-run multi-sport competitions. $^{2}$ ODTs are of relatively short duration (around $100 \mathrm{~min}$ for men and $110 \mathrm{~min}$ for women); consist of a $1.5 \mathrm{~km}$

\section{What are the new findings?}

- Bad weather is good for training quality.

- Dirty water means no training.

- Nutritional intake adaption is a type of training; are you doing it?

- Beware of the asynchronous training rhythm.

- Situational awareness training might undo the curse of the 'asphalt tattoo'.

- 'Mood sensitivity' is a valuable attribute in a group-training context.

- Group competition is healthy, but 'psychological slavery' must be recognised and avoided.

- Sponsorship creates training quality stress.

How might our findings impact on clinical practice in the near future?

- Utilising a biopsychosocial framework to plan and maintain training facilitates injury prevention at the primary, secondary and tertiary levels.

- The training vortex can point out unexpected training threats at the group and individual level, to which support staff can then respond in order to avoid training quality breakdowns.

swim, $40 \mathrm{~km}$ cycle and $10 \mathrm{~km}$ run; and are distinguishable by the use of standard road bicycles, legal bunching and drafting. ${ }^{34}$

Critical to realising performance goals on the world ODT stage is a highquality training programme..$^{5}$ However, first achieving and then maintaining optimal training levels throughout a punishing competition season is challenging and a constant work in progress. Coaches and support staff face a myriad of potential threats across physical (biological), psychological and social domains, as negative exposures to athlete group dynamics or mental exhaustion are potentially just as 
devastating to training schedules as travel fatigue and even accidental trauma. ${ }^{7-9}$

It stands to reason that working within a comprehensive framework populated by relevant factors that may impact training before and during the competitive season would help realise training goals by reducing unanticipated negative occurrences. However, even at the elite level, this does not appear to be standard practice.

In 2013, the Danish Triathlon Federation entered into a partnership with the University of Southern Denmark to create Tri Team SDU. ${ }^{10}$ This squad-based programme offers athletic scholarships to Scandinavian triathletes with the potential to compete at the international level. Benefits include access to training staff and facilities, injury management and preventative healthcare, collegial housing, nutritional support, financial aide and flexible programmes of study. Athletes gain entry into the programme based on performance parameters in swimming and running, as well as coaching staffs' evaluations. ${ }^{11}$ To facilitate their transition into international competition, a line of inquiry was launched aimed at optimising training in this context. ${ }^{12}$

In this investigation, our specific of objectives were to describe and explore the factors perceived as influential on training quality among individuals enrolled in a university-based elite Scandinavian triathlete development programme over the course of a competitive season.

\section{METHODS}

Design

We devised an explorative qualitative investigation suited to capturing both group and individual training experiences over the course of a competition season. ${ }^{13-}$

\section{Sample}

All 10 triathletes who formed Tri Team SDU at the time of the investigation were sampled; however, 2 were unable to attend the preseason training camp in January 2015. Thus, our sample consisted of eight participants $(n=8)$.

\section{Data collection}

We conducted and audio-recorded a focus group at the preseason training camp followed by face-to-face individual interviews at the start and end of the competitive season. Through the focus group, themes were rapidly developed and group interactions observed, whereas individual interviews provided an opportunity for deeper thematic exploration and the expression of views of a more sensitive nature. ${ }^{17}$ The second set of interviews were aimed at observing potential temporal thematic fluctuations that may have occurred during the competitive season. ${ }^{18}$

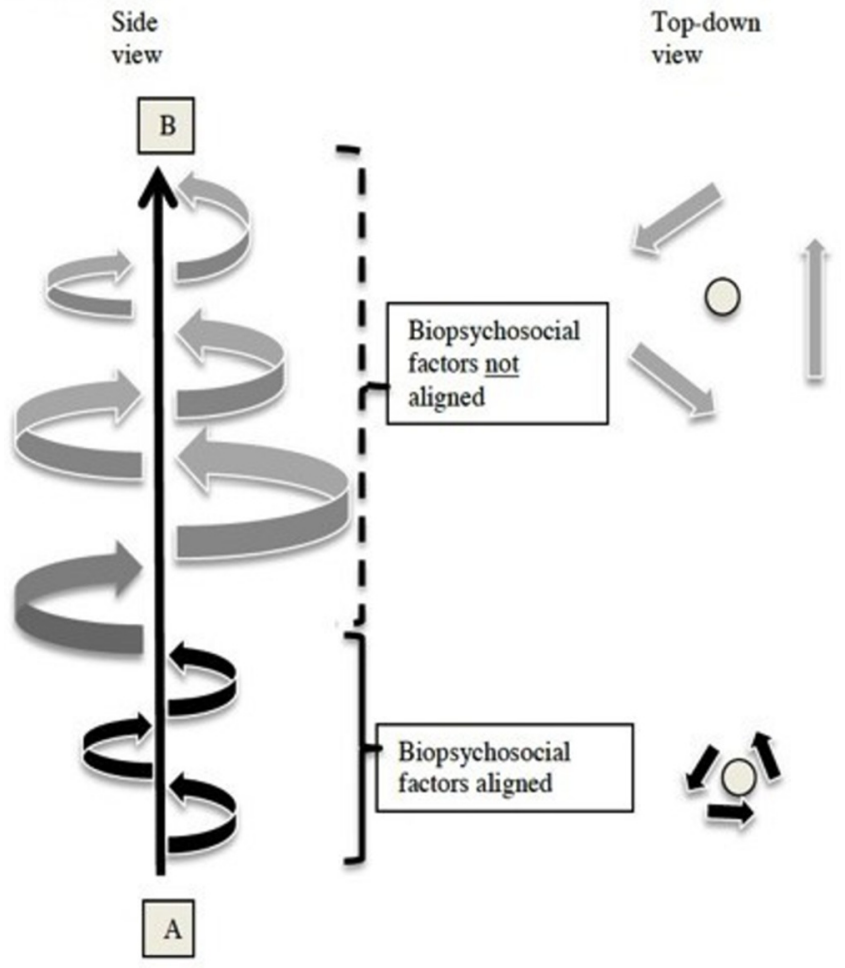

Figure 1 'Vortex construct' used to visually communicate the influence of biopsychosocial influences on the achievement of training goals.

At the focus group, the participants were asked to provide insights into factors, both positive and negative, they considered relevant to their training. To operationalise the task, a novel visual communication tool, the 'vortex concept', was used to illustrate the relationship between training and the potentially broad range of factors that may influence its progression (figure 1). ${ }^{19}$ In brief, an athlete's training goal is planned to run from point ' $A$ ' to point ' $B$ '. If all factors are tightly aligned (biological, psychological and social), the training runs smoothly and goals are achieved as planned and a 'narrow vortex' (represented by the black arrows) is achieved. However, when factors are not well aligned, a 'wide vortex' effect developsthat results in training goals being delayed or not being met (represented by the grey arrows).

Once transcribed, the focus group was independently coded by two of the authors (TH and MB) and a code list developed. The code list was also independently categorised into three domains: biological, psychological and social factors (by TH and MB). The biological domain included any physical factor that could have affected the function and the behaviour of the triathlete. Factors that had the potential to affect attitude, behaviour and function of the triathlete as a result of thoughts and/or feelings were coded in the psychological domain. The social domain involved factors that had the potential to affect thoughts and behaviours in social situations. Disagreements of the coding were 
Box An interview schedule excerpt from dealing with 'own expectations':

In the focus group there was a lot of talk of wanting to do well at school, training, study groups, family life etc. Have you experienced that your own expectation to achieve this has had a negative effect on your training?

resolved through a consensus group meeting with $\mathrm{TH}$, $\mathrm{MB}$ and $\mathrm{CM}$.

The interview schedule that emerged from the focus group's code list consisted of a series of open-ended questions, which the athletes were asked to elaborate on box.

The second round of interviews (conducted by AHB) used a similar interview guide but focused on 'what has changed'. All participants were interviewed during the first round of interviews, and in keeping with the constant comparison approach, ${ }^{17}$ the second round of interviews was concluded when thematic data saturation was observed. ${ }^{20}$

\section{Analysis}

We initially codified text data inductively (open coding), after which a deductive categorisation of codes as biological, psychological or social subdomains was conducted. We then generated code families from cooccurring codes and finally, through the creation of visual networks, generated themes. We made use of computer-assisted data analysis software (Atlas Ti 6.8) throughout the analysis process. ${ }^{18}$

\section{Ethics}

Data were collected confidentially and anonymised in compliance with the stipulations of the Danish Data Protection Agency for the procurement and storage of interview data.

\section{RESULTS}

The focus group interview lasted $52 \mathrm{~min}$, and the individual interviews between 35 and $60 \mathrm{~min}$. Follow-up interviews were conducted with five triathletes (data saturation occurred at this point) and lasted between 16 and $25 \mathrm{~min}$. Additional observations were noted during the follow-up with respect to 'the weather', 'family' and 'expectations'.

\section{Categorisation and factors}

Based on the responses, 14 unique issues relevant to triathlete training quality were identified and categorised as primarily biological (table 1), psychological (table 2) or social in nature (table 3).

During our analysis, it became relevant to unpack observations around 'the group' into four subcategories, these being group engagement, competition and relationships and raise these to the level of factors. We thus identified 17 context-relevant factors. Of these, six were perceived as effecting training directly (figure 2, black-coloured text). 'Travel \& sickness', 'fluids \& nutrition', 'sleep \& recovery' and 'fear of injury' were perceived as direct-negative influences and 'coaching staff' and 'living on campus' as direct-positive influences.

The remaining 11 factors (figure 2, grey-coloured text) appeared to influence thoughts and/or behaviours, which in turn led to interaction effects related to training. 'Mood' issues were reported as mainly negative and were highly dependent on 'fluids \& nutrition' as well as 'sleep \& recovery'; however, 'The weather', 'group 'engagement' and 'group relationships' were perceived as mainly positive. The 'expectations of others' was perceived as borderline negative, whereas 'family' was borderline positive. The athletes' 'own expectations', 'group competition', their 'sense of responsibility', individual 'academic performance' and 'young life' were neutral based on our data. When viewed on a 'negative-to-positive' continuum, our data (figure 2) indicated that factors influencing training directly appeared polarised, either clearly negative or positive, whereas the indirect (mediating) factors tended to create a spectrum between negative and positive.

\section{Emerging themes}

Across the biopsychosocial domains, we identified 10 themes relevant to the maintenance of high-quality training. These were: 'the cold weather ritual', 'digestive system conditioning', 'the curse of the night owl', 'the strings attached to sponsorship', 'my coach-my rock', 'mood maintenance', 'the asynchronous training rhythm', 'psychological slavery', 'the legacy of the asphalt tattoo' and 'the tension of family and friends'.

\section{'Cold weather tempering'}

Adverse weather conditions had no perceived impact on consistent training. Rather, maintaining their training schedule throughout the northern European winter was perceived as a right of passage, conferring on each athlete a psychological resilience advantage over opponents who train exclusively in temperate conditions (P5;L23-26, P6;L12-13).

\section{No guts no training glory. .}

The digestive system was of particularly import to our athletes. Gastrointestinal tract infections (P1; L116117, P7; L24-25) were reported as a postcompetition sequelae with the potential to completely derail training. Furthermore, to test their tolerances for carbohydrate replacements and legal stimulants, athletes 'train the gut'. This form of experimentation is undertaken during training and may affect training 
Table 1 Key codes and quotes supporting the issues categorised as pertinent to the biological subdomain

\begin{tabular}{|c|c|c|}
\hline Code & Key quote(s) & Reference \\
\hline $\begin{array}{l}\text { The } \\
\text { weather }\end{array}$ & $\begin{array}{l}\text { '... if it snows and is really icy and you could crash on your bike, then one ought to train } \\
\text { indoors instead.' } \\
\text { '... if the weather is bad. . your opponent will not be training, it gives me a motivation to } \\
\text { train. . . that will make me better and tougher than them.' }\end{array}$ & $\begin{array}{l}\text { P6; L12-13 } \\
\text { P5; L23-26 }\end{array}$ \\
\hline $\begin{array}{l}\text { Travel \& } \\
\text { sickness }\end{array}$ & $\begin{array}{l}\text { '... when I just finish a race and have a period, where I do not have to perform as much, } \\
\text { it is often then I get influenza...' } \\
\text { '... last year I was in xxx (city in South-America) and took a parasite home, which took } \\
\text { me out for a total of maybe three months...' }\end{array}$ & $\begin{array}{l}\text { P1; L116-117 } \\
\text { P7; L24-25 }\end{array}$ \\
\hline $\begin{array}{l}\text { Fluids } \\
\& \text { nutrition }\end{array}$ & $\begin{array}{l}\text { '... my body [reacts] really poorly with caffeine, and that I discovered during a } \\
\text { competition, because I had not tried it at training. .' }\end{array}$ & P4; L96-98 \\
\hline $\begin{array}{l}\text { Sleep \& } \\
\text { recovery }\end{array}$ & $\begin{array}{l}\text { '... Thursday morning training, swimming, where we jump in the water at } 6.30 \text { AM. . I } \\
\text { am a b-person, so for me it is really hard.' }\end{array}$ & P3; L156-157 \\
\hline
\end{tabular}

$\mathrm{L}$, transcript line number; $\mathrm{P}$, participant interview number.

Table 2 Key codes and quotes supporting the issues categorised as pertinent to the psychological subdomain

\begin{tabular}{|c|c|c|}
\hline Code & Key quote(s) & Reference \\
\hline Expectations & $\begin{array}{l}\text { '... I am one of those that don't really care and just says "whatever".' } \\
\text { '... if there were no expectations to my performance, I do not think I would bother } \\
\text { doing that much training.' } \\
\text { 'If you do not get the } 30.000 \text { kroner from your sponsors, because they demand some } \\
\text { specific results, then [thing] look really bad. And you therefore you feel pressured to go } \\
\text { out and do something rushed [which] your body cannot keep up with.' }\end{array}$ & $\begin{array}{l}\text { P8; L176 } \\
\text { P5; L34-35 } \\
\text { P4; L277-280 }\end{array}$ \\
\hline $\begin{array}{l}\text { Coaching } \\
\text { staff }\end{array}$ & $\begin{array}{l}\text { '... it is important to get my techniques adjusted (referring to the coaching staff) } \\
\text { because I think that is a good way to improve [myself]...' } \\
\text { '... we (the coaching staff and themself) can evaluate after each training session how it } \\
\text { has been. ..' } \\
\text { '... it means a lot that I have a good relationship with them (coaching staff). That they } \\
\text { understand me and I understand them... no signals are misunderstood.' }\end{array}$ & $\begin{array}{l}\text { P3; L285-286 } \\
\text { P4; L224-226 } \\
\text { P6; L232-234 }\end{array}$ \\
\hline Mood & $\begin{array}{l}\text { 'Not eating correctly and not getting enough sleep... the body does not perform well } \\
\text { and the mood goes down.' }\end{array}$ & P5; L686-688 \\
\hline The group & $\begin{array}{l}\text { '. . you need to be on all the time, be in the correct mood. ..' } \\
\text { 'The more you are a part of the group, the more are they group willing to pick you up if } \\
\text { there is something wrong.' } \\
\text { 'If all went around mad [grumpy] it would not be sustainable. . . but it can also be fun if } \\
\text { there is someone that sometimes is a bit negative...' } \\
\text { '... It is annoying if all the others are doing extremely well and yourself are wrecked } \\
\text { and you do not understand why you do not have as much energy as them.' } \\
\text { '... It motivates me a lot, just to be able to hang on for } 5 \text { min or } 10 \text { min, it is definitely } \\
\text { what motivates me most in the training.' } \\
\text { 'Yeah, I feel the thing that works best, is when there is someone better than myself and } \\
\text { someone older than yourself.' } \\
\text { 'Even when they swam slower sometimes, I just had it in my head that I couldn't beat } \\
\text { them' } \\
\text { '... If I didn't have them it would be difficult to just get myself together to go train as } \\
\text { much. .' } \\
\text { '... if I did not have the team, I wouldn't have made it to where I am now.' }\end{array}$ & $\begin{array}{l}\text { P3; L236-237 } \\
\text { P8; L244-245 } \\
\text { P8; L314-321 } \\
\text { P6; L372-374 } \\
\text { P7; L698-699 } \\
\text { P8; L512-513 } \\
\text { P4; L574-575 } \\
\text { P3; L701-703 } \\
\text { P7; L592-593 }\end{array}$ \\
\hline Fear of injury & $\begin{array}{l}\text { 'There are some things I don't dare to do when we cycle downhill. . I I brake much } \\
\text { more than the others, because I feel unsafe.' }\end{array}$ & P4; L548-550 \\
\hline
\end{tabular}

$L$, transcript line number; $P$, participant interview number. 
Table 3 Key codes and quotes supporting the issues categorised as pertinent to the social subdomain

\begin{tabular}{|c|c|c|}
\hline Code & Key quote(s) & Reference \\
\hline Responsibility & $\begin{array}{l}\text { '... it is his responsibility too plan [training] so I can perform. . . they would like us to } \\
\text { trust them... In that way they can live up to the task.' }\end{array}$ & P1; L593-595 \\
\hline Campus life & $\begin{array}{l}\text { 'Definitely the time, first of all; And with respect to restitution especially with small } \\
\text { power naps, it is really good' } \\
\text { '... I don't believe I would have been where I am today, if it wasn't for how close I } \\
\text { live to the things I do.' }\end{array}$ & $\begin{array}{l}\text { P2; L536-537 } \\
\text { P8; L381-382 }\end{array}$ \\
\hline $\begin{array}{l}\text { Academic } \\
\text { performance }\end{array}$ & $\begin{array}{l}\text { 'I feel like I could live without school. That is only being a triathlete...' } \\
\text { '... if it doesn't go well in school ... it affects me a lot, you need to have balance in } \\
\text { training, at school and at home.' }\end{array}$ & $\begin{array}{l}\text { P6; L547-548 } \\
\text { P8; L409-411 }\end{array}$ \\
\hline Family & $\begin{array}{l}\text { 'It means a lot for me that I have my family's support-else it could be hard spending } \\
\text { that much time on it.' } \\
\text { 'I believe I'm more focused (on my training) in my familiar surroundings (referring to } \\
\text { the university) than when I'm going home.' } \\
\text { '... if they [family] don't like it, I would do it anyways.' }\end{array}$ & $\begin{array}{l}\text { P4; L472-473 } \\
\text { P7; L544-545 } \\
\text { P5; L192-193 }\end{array}$ \\
\hline 'Young life' & $\begin{array}{l}\text { '... I don't have a problem with not staying out in the city until 3am in the morning.' } \\
\text { '... we are part of this Syddansk elite on Uni (referring to Tri team SDU), then there is } \\
\text { also a wide accepting of it in the study group...' } \\
\text { 'I have a lot of friends outside triathlon and it is difficult to find time for them all. It is } \\
\text { something that really bothers me.' } \\
\text { '... then you do not only have one thing to focus on and one thing where you put all } \\
\text { your concerns. It is important to have other stuff.' }\end{array}$ & $\begin{array}{l}\text { P1; L763-764 } \\
\text { P8; L483-484 } \\
\text { P4; L512-513 } \\
\text { P2; L583-584 }\end{array}$ \\
\hline
\end{tabular}

$\mathrm{L}$, transcript line number; $\mathrm{P}$, participant interview number.

quality negatively. However, it is perceived as a necessary practice to avoid unwelcome race-day surprises.

\section{The curse of the night owl}

There was broad agreement that adequate sleep and recovery constitutes a crucial factor in coping with a high training volume and intensity (P4;L96-98). In this regard, living close to the university and its training and treatment facilities directly impacted the groups' ability to sustain their training load as the athletes are able to rest during the day and avoid feeling 'worn out' (P2; L536-537, P8; L381-382). However, it would appear that, in an effort to avoid physical and mental fatigue, athletes who are night owls by nature make use of this strategy more often (P3; L156-157).

\section{'The strings attached to sponsorship'}

Expectation-related factors were generated internally via the athlete's 'own expectations' but also externally via 'the expectations of others'. With respect to the former, we observed both perfectionist, those who tended to be critical of perceived training underperformance (P5; L34-35) and laissez faire attitudes to training and performance (P8; L176). We noted a similar response with respect to the importance of academic performance. For some triathletes, it was considered to be one part of their life and to be balanced with the rest (P8; L409-411), whereas others identified themselves primarily as triathletes and experienced little tension when their academic performance was not at the same level as their triathlon endeavours (P6; L547-548). On the whole, 'own expectations' exerted either little (neutral) or a positive influence on the training ethic in this context.

With respect to the latter, however, we observed that individually sponsored athletes, despite the fatigue and/or injuries they sustain during the season felt pressured into training and competing in order to maintain sponsorship agreements. Sponsor expectation was thus perceived as an external catalyst for overtraining (P4; L277-280).

\section{'My coach-my rock'}

For our respondents, the positive influence of the coaching staff on training was grounded in the constancy of support they received. This was operationalised in the planning (P1; L593-595), constant communication (P6; L232-234), technique development (P3; L285-286) and the coaching staff's accessibility to provide session-by-session progress monitoring and evaluation (P4; L224-226).

Please insert a line break here.

Squad members developed friendship ties with one another, which extended beyond the level of training partners (P3; L701-703). These relationships appeared to contribute to the training by re-enforcing mental stamina (P7; L592-593). However, the influence of the group dynamic on the triathletes' training emerged as a complex issue, with respect to maintaining training quality. Indicative of this complexity are the notions of 


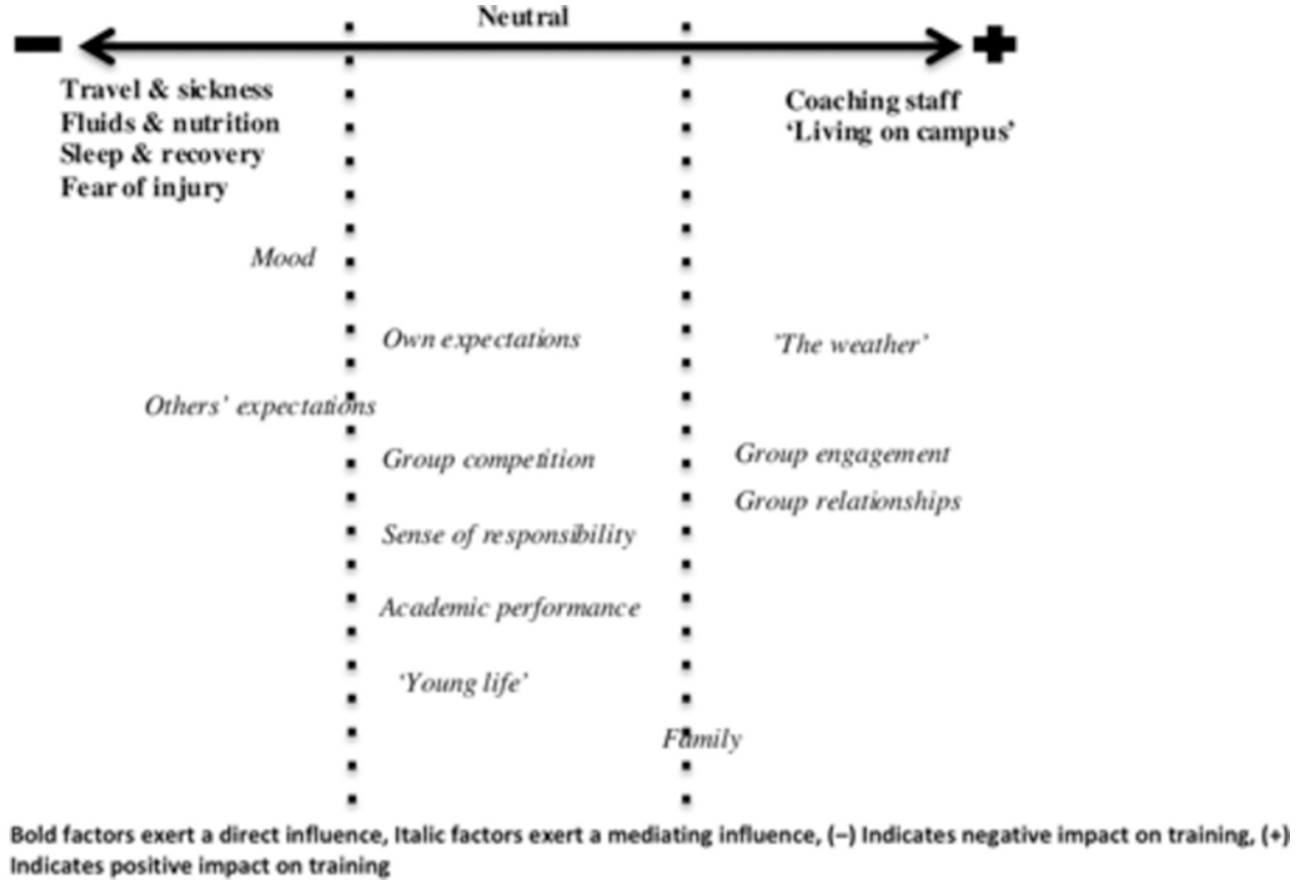

Figure 2 Factors identified presented on 'influence on training' spectrum.

'mood maintenance, 'the asynchronous training rhythm' and 'psychological slavery'.

\section{'Mood maintenance'}

The group clearly articulated that a negative effect on mood status gives rise to a reduction in training impetus and if not counteracted effectively resultsin poor training quality (P5;L686-688). In this regard, the capacity of the group to lift each other's mood was perceived as an important positive mediator for maintaining and achieving training goals.

Engaging with the group as a team member requires a continued effort from each triathlete to put their best foot forward (P3; L236-237). Developing a type of 'mood awareness', both to one's own and that of team members, allowes the triathlete to access and feed off of the squad's shared energy when experiencing an 'off' day (P8; L244-245), thus allowing the triathlete to maintain quality training they would not have enjoyed had they been on their own (P8; L314-321).

\section{'The asynchronous training rhythm'}

However, when a triathlete's physiological 'training rhythm' becomes asynchronous with the rest of the team, the group dynamic can impact negatively, as the triathlete was unable to maintain the intensity of the training session (P6; L372-374).

\section{'Psychological slavery'}

Group competition can influence training experiences both positively or negatively. Some triathletes clearly benefited from responding to the challenge of a stronger team member (P7; L698-699, P8; L512-513), whereas others began to experience a 'psychological slavery' when forced to play second fiddle to a discipline-dominant team member for a too long of a period (P4; L574-575).

\section{'The legacy of the asphalt tattoo'}

Experiencing an injury resulted in fear of a repeat episode, and as a result, pushing the limits during training became mentally challenging (P4; L548-550). This was particularly the case for those who had experienced a serious bicycle accident and in reference to a friction burn scar, a so-called 'asphalt tattoo', served as a reminder.

\section{The tension of family and friends}

While it was noted that maintaining training regimens out of the structured, campus environment was challenging, family appeared to psychologically anchor the triathlete's dedication to their sporting endeavour (P4;472-473, P7; L544-545). However, on follow-up, we observed emergent tension in instances where family members questioned the amount of time dedicated to training in the sport (P5; L192-193).

We also observed dissonance in the group with respect to the issue of their 'young life' beyond triathlon. Some triathletes experienced no tension in maintaining a spartan dedication to their training (P1; L763-764), a view grounded in a sense of responsibility and realisation of the group's privileged position (P8; L483-448). However, others experienced cancelling their social engagements as more disruptive to themselves (P4; L512-513) and that a multi- 
dimensional young life was important in order to maintain a healthy sense of perspective (P2; L583-584).

\section{DISCUSSION}

Given its exploratory nature, the contribution of this investigation lies in its hypothesis-generating potential. Thus, in relation to our findings and taking into account existing literature, we offer the following salient issues as food for thought.

Considering the importance of heat acclimatisation, it would have been reasonable to observe this factor among those perceived as a training challenge. ${ }^{21} 22$ Instead, this group alluded to a ritualistic practice of training through challenging climatic conditions, in this instance, the northern European winter. As rituals are known to contribute toward physical and mental well-being, social solidarity and cohesion, ${ }^{23}$ it would be interesting to observe whether valued ritualistic practices exist within other squad-based triathlon programmes.

The significant risk to general health and training posed by swimming in sewage-polluted water is selfevident. ${ }^{24}{ }^{25}$ While vigilance strategies such as wound protection and avoiding competitions preceded by major meteorological events (for example flooding) may help, more sophisticated strategies should be considered. In this regard, the use of wearable technology to measure exposure might be worth exploring.

Athletes who participate in events of longer than $90 \mathrm{~min}$ are encouraged to consume carbohydrates both precompetition and during competition. ${ }^{4}$ However, the nature of ODTs often limits opportunities for consuming foodstuffs given the relatively short length of time. As a result, both preparticipation and race intake planning become even more important. While our group was clearly aware of the importance of establishing tolerances for designer energy foods, presumably due to periodic changes in dietary sponsorships, we elicited no feedback as to whether general food and nutrition intake adaptation strategies were systematically considered in the planning and implementation of training routines.

Our group was acutely aware of the debilitating effects of poor sleep and recovery as previously reported. ${ }^{26}$ In this regard, evening chronotypes appeared vulnerable to early morning practice session fatigue. Furthermore, while power napping was a recognised strategy for recovery between training sessions, ${ }^{27}$ this practice may lead to sleep debt reduction and therefore may not be an optimal long-term recovery strategy to maintain training quality. It is unclear from our data whether our athletes are aware of the existing debate around napping ${ }^{27}$ or whether they employ specific sleep hygiene practices, such as sleep regularity training or presleep limits on the use of electronic devices, in order to enhance recovery over night. ${ }^{26}$ A novel observation was the notion of an athlete that has fallen into 'asynchronous training rhythm', which perhaps shares a link with the issue of athlete sleep and recovery. In this state, the athlete's cycle of fatigue and restitution does not overlap with the rest of the training group, making it difficult for the individual to maintain training quality.

Risk of a crash during cycling poses arguably the greatest threat to injury to the triathlete. ${ }^{8}$ We similarly observed this as an issue relevant to training quality, in particular when the athlete previously experienced a serious crash and termed the phenomenon 'the legacy of the asphalt tattoo'. Given its wide-ranging impact, it would be prudent to determine individual fear of injury status and, in addition, an investment of resources on technical skills accrual as well as race situational awareness training might be considered.

Consensus exists around the notion that 'mental fortitude to push physical limits' is an essential psychological characteristic of the professional athlete. ${ }^{28}$ In general and in keeping with Barefield and McCallister, ${ }^{29}$ group members were perceived as supportive to the individuals' training endeavours. Our data indicated that this benefit of group life appears to be informally practised by developing an attribute referred to as 'mood maintenance'. We did, however, observe evidence that suggested 'psychological slavery' might lower the quality of training in those who experienced long-term dominance. An important salient issue for future research is the occurrence of negative psychological mindsets in squad-based programmes. ${ }^{3}$

Being sponsored is an external symbol of success for the individual athlete. However, implicit to sponsorship is the expectation for brand exposure. ${ }^{30}$ Our responder athletes provided some insight into this tension, as those with individual sponsorship felt pressured to train and compete beyond their limits. As one of the core functions of Tri Team SDU programme is to reduce athlete pressure, the advantages and disadvantages of external and individual sponsorship warrant further inquiry. Moreover, as nutritional sponsorship necessitates a period of nutritional intake adaptation, mid-season changes require due consideration with respect to training impact.

\section{Limitations}

We assumed that our participants would require a stimulus to think beyond the physical and introduced the vortex concept. This may not have been necessary; however, the athletes enjoyed creating their own personal vortex, and therefore, its usefulness beyond visual communication might be worth exploring further. The unique setting of this investigation precludes the transferring of our findings broadly to other elite triathlon contexts.

\section{CONCLUSIONS}

By nuancing issues influencing training through a biopsychosocial lens, this investigation highlighted 10 themes, relevant to achieving training goals over the 
course of a competitive season. Our study makes a context-specific contribution to existing literature, and the salient issues, due to their significant potential for influencing the realisation of training goals and by extension athletic performance, warrant further investigation.

Acknowledgements The authors thank the members and coaching staff of Tri Team SDU for their cooperation.

Contributors $\mathrm{CM}$ took primary responsibility for the design and execution of the study and writing of the manuscript. TH and AHB were involved with the execution of the study and editing of the manuscript. EB contributed to the writing and editing of the manuscript.

Competing interests None declared.

Patient consent Obtained

Ethics approval Danish Data Protection Agency.

Provenance and peer review Not commissioned; externally peer reviewed.

Open Access This is an Open Access article distributed in accordance with the Creative Commons Attribution Non Commercial (CC BY-NC 4.0) license, which permits others to distribute, remix, adapt, build upon this work noncommercially, and license their derivative works on different terms, provided the original work is properly cited and the use is non-commercial. See: http:// creativecommons.org/licenses/by-nc/4.0/

(C) Article author(s) (or their employer(s) unless otherwise stated in the text of the article) 2017. All rights reserved. No commercial use is permitted unless otherwise expressly granted.

\section{REFERENCES}

1. Knechtle $R$, Rüst CA, Rosemann $T$, et al. The best triathletes are older in longer race distances-a comparison between Olympic, Half-Ironman and Ironman distance triathlon. Springerplus 2014;3:538.

2. http://wts.triathlon.org/. International Triathlon Union; 2017. http:// wts.triathlon.org/prize_money.

3. Wu SS, Peiffer JJ, Brisswalter J, et al. Factors influencing pacing in triathlon. Open Access J Sports Med 2014;5:223-34.

4. Cox GR, Snow RJ, Burke LM. Race-day carbohydrate intakes of elite triathletes contesting olympic-distance triathlon events. Int $J$ Sport Nutr Exerc Metab 2010;20:299-306.

5. Greenleaf C, Gould D, Dieffenbach K. Factors influencing Olympic performance: interviews with Atlanta and Negano US Olympians. $J$ Appl Sport Psychol 2001;13:154-84.

6. Millet GP, Candau RB, Barbier B, et al. Modelling the transfers of training effects on performance in elite triathletes. Int $J$ Sports Med 2002;23:55-63.

7. Woodman T, Hardy L. A case study of organizational stress in elite sport. J Appl Sport Psychol 2001;13:207-38.

8. Gosling CM, Donaldson A, Forbes $A B$, et al. The perception of injury risk and safety in triathlon competition: an exploratory focus group study. Clin J Sport Med 2013;23:70-3.
9. Ruiz-Tendero G, Salinero Martín JJ. Psycho-social factors determining success in high-performance triathlon: compared perception in the coach-athlete pair. Percept Mot Skills 2012;115:865-80.

10. Tri Team SDU online. Dansk Triatlon Forbund. 2015 http://www. triatlon.dk/elite/tri-team-sdu/.

11. Krüger M. Triteam SDU scholarship criteria. In: Myburgh C, editor 2017.

12. Waddell G. Preventing incapacity in people with musculoskeletal disorders. Br Med Bull 2006;77-78:55-69.

13. Daly J, Willis K, Small R, et al. A hierarchy of evidence for assessing qualitative health research. J Clin Epidemiol 2007;60:43-9.

14. Caelli K. The changing face of phenomenological research: traditional and American phenomenology in nursing. Qual Health Res 2000:10:366-77.

15. Caelli K, Ray L, Mill J. 'Clear as mud': toward greater clarity in generic qualitative research. Int J Qual Methods 2003;2:1-13.

16. Creswell JaPC VL. Designing and conducting mixed methods research. 2nd ed. Thousan Oaks: Sage, 2011:457.

17. Patton M. Qualitative Research \& Evaluation Methods. 3rd ed. Thousand Oaks: Sage, 2002.

18. Babbie EaM J. The practice of social research. Cape Town: Oxford University Press South Africa, 2001

19. Lazard AJ, Bamgbade BA, Sontag JM, et al. Using visual metaphors in health messages: a strategy to increase effectiveness for mental illness communication. J Health Commun 2016;21:1260-8.

20. Myburgh C. A qualitative exploration of key informant perspectives regarding the nature and impact of contemporary legislation on professional development: a grounded theory study of chiropractic in Denmark. J Manipulative Physiol Ther 2014;37:383-95.

21. Dallam GM, Jonas S, Miller TK. Medical considerations in triathlon competition: recommendations for triathlon organisers, competitors and coaches. Sports Med 2005;35:143-61.

22. Bradford CD, Lucas SJ, Gerrard DF, et al. Swimming in warm water is ineffective in heat acclimation and is non-ergogenic for swimmers. Scand J Med Sci Sports 2015;25(Suppl 1):277-86.

23. Sohi KK, Singh P, Bopanna K, et al. Ritual participation, sense of community, and social well-being: A study of seva in the sikh community. J Relig Health 2017 (Epub ahead of print: 2 Jun 2017).

24. Harder-Lauridsen NM, Kuhn KG, Erichsen AC, et al. Gastrointestinal illness among triathletes swimming in non-polluted versus polluted seawater affected by heavy rainfall, Denmark, 2010-2011. PLoS One 2013;8:e78371.

25. Pagès $F$, Larrieu S, Simoes J, et al. Investigation of a leptospirosis outbreak in triathlon participants, Réunion Island, 2013. Epidemiol Infect 2016;144:661-9.

26. Sargent C, Lastella M, Halson SL, et al. The impact of training schedules on the sleep and fatigue of elite athletes. Chronobiol Int 2014;31:1160-8.

27. Correa A, Ruiz-Herrera N, Ruz M, et al. Economic decision-making in morning/evening-type people as a function of time of day. Chronobiol Int 2017:34:139-47.

28. Wiese-Bjornstal DM. Psychology and socioculture affect injury risk, response, and recovery in high-intensity athletes: a consensus statement. Scand J Med Sci Sports 2010;20(Suppl 2):103-11.

29. Barefield S, McCallister S. Social support in the athletic training room: athletes' expectations of staff and student athletic trainers. $J$ Athl Train 1997;32:333-8.

30. Pinsky I, Noto AR, Botéquio de Moraes MC, et al. Alcohol industry sponsorship of University Student Sports Clubs in Brazil. J Stud Alcohol Drugs 2017;78:306-12. 


\section{Correction: Cracking the code for maintaining quality training in Olympic distance triathlon: lessons learnt from a squad of elite Scandinavian athletes}

Corrie Myburgh, Tobias Hansen, Anders Holm Beck, et al. Cracking the code for maintaining quality training in Olympic distance triathlon: lessons learnt from a squad of elite Scandinavian athletes. BMJ Open Sport $\mathcal{E}$ Exercise Medicine 2017;3(1):e000274; DOI: 10.1136/bmjsem-2017-000274.

The authors would like to acknowledge the contribution of Martin Bager Bertelsen in the development of their visual communication tool for conveying the 'vortex concept' and furthermore for his efforts during interview data collection in this investigation.

Open Access This is an Open Access article distributed in accordance with the Creative Commons Attribution Non Commercial (CC BY-NC 4.0) license, which permits others to distribute, remix, adapt, build upon this work non-commercially, and license their derivative works on different terms, provided the original work is properly cited and the use is non-commercial. See: http://creativecommons.org/licenses/by-nc/4.0/

(c) Article author(s) (or their employer(s) unless otherwise stated in the text of the article) 2018. All rights reserved. No commercial use is permitted unless otherwise expressly granted.

BMJ Open Sport Exerc Med 2018;4:e000274corr1. doi:10.1136/bmjsem-2017-000274corr1

Check for updates 